\title{
Heterogeneity in IoT-Based Smart City Designs
}

\author{
https://doi.org/10.3991/ijim.v13i12.9763 \\ Mais Haj Qasem $\left({ }^{\bowtie}\right)$, Wesam AlMobaideen \\ The University of Jordan, Amman, Jordan \\ mais hajqasem@hotmail.com
}

\begin{abstract}
Smart city is a strategy of supporting a new way of living using data collected from different types of electronic devices. Subsequently, such data are analyzed and utilized to enable efficient resource usability and service optimization. Various applications, such as traffic planning, crowd monitoring, public health care, security, economy, and urban planning, are elaborated in smart cities. Thus, various requirements are needed to incorporate and facilitate efficient development of these applications in the smart city design. Smart cities can be distinguished via the requirements supporting these applications. This study establishes the requirements of smart cities in relation to the involved applications and their influence on the smart city design. Moreover, this research provides a list of smart city requirements and discusses the potentials of various network architectures to facilitate such requirements. The existing smart city designs are evaluated and compared on the basis of the requirements and architectures.
\end{abstract}

Keywords—Fog Computing, Smart City, Cloud, Internet of Thing.

\section{$1 \quad$ Introduction}

The Internet of things (IoT) is a physical network of devices that are connected, accessed, and controlled remotely, which allows the integration of physical devices to be computer-based systems. Things can refer to a wide range of devices, such as sensors, cameras, cars, and home equipment. The IoT field of study covers the current and future huge increments in devices, which can be used to collect data to enhance the services provided for humans in various fields [1]. Having such technology, governments worldwide are motivated to advance services provided to their citizens by implementing the so-called smart cities. Smart city is a strategy of supporting a new way of living using data collected from different types of electronic devices. Subsequently, such data are analyzed and utilized to enable efficient resource usability and service optimization. The concept of smart city was proposed to address the problem of urban population growth globally [2]. Accordingly, various applications, such as traffic planning, crowd monitoring, public health care, security, economy, and urban planning, are cooperated in smart cities as illustrated in Figure 1 [3]. Each of these applications addresses different domains, data, and applications; therefore, interoperability, openness, and convergence problems will be raised [4]. 
A set of requirements have been established to develop a robust design of a smart city. Interoperability, openness, convergence, and scalability in adopting new devices, technologies, and environments are important requirements for a smart city. Other requirements can also be concluded through a careful analysis of smart city services, applications, domains, and goals.

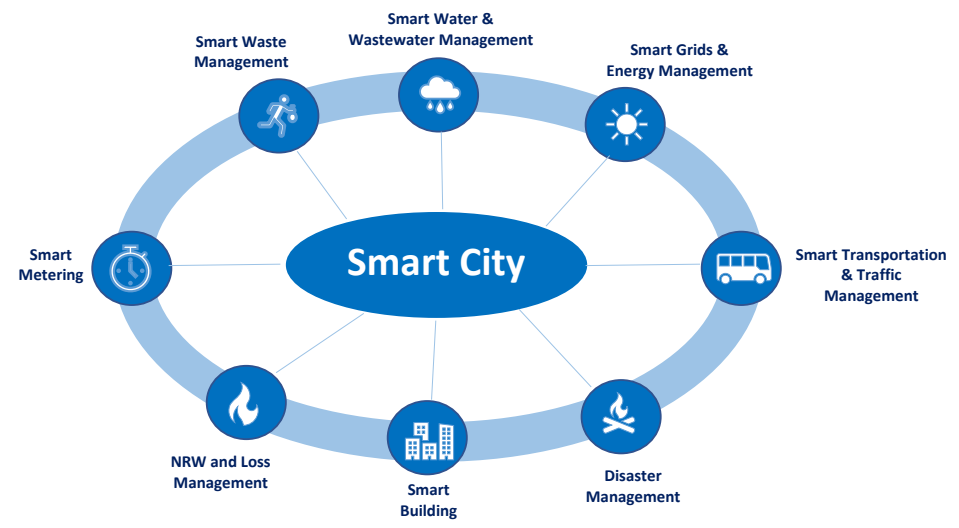

Fig. 1. Smart City Applications [3]

Various designs for smart cities have been proposed. For example, Vlacheas, Giaffreda [5] proposed "a framework that will empower the Internet of Things to better support sustainable smart city development," Sanchez, Muñoz [6] presented the "deployment and experimentation architecture of the Internet of Things experimentation facility being deployed at Santander city," and Lea and Blackstock [7] "introduce the general notion of IoT hubs and then discusses our work to generalize our IoT hub as a Smart City." These designs require evaluation, assessment, and comparison. One of the best approaches to compare among these designs is to analyze their capabilities in addressing the requirements discussed above.

The capability of a smart city design can be evaluated using the network architecture adopted in the development of that city. Architectures determine the features that a smart city can attend in a pool of features established as the bases of smart cities in the literature. Four different network architectures exist in the smart city domain, namely, autonomic, ubiquitous, application-layer overlay, and serviceoriented network architectures; notably, they differ in the connectivity models, QoS, applicability, and suitability for smart city applications [8].

This study evaluates and compares existing smart city designs on the basis of the requirements satisfied by each design with reference to the network architecture utilized in each design. The requirements of smart cities are first identified with reference to existing surveys that study these requirements. The network architectures are then evaluated on the basis of their capabilities in addressing these requirements. The existing designs are finally evaluated and compared with reference to the utilized architecture and the specification of the design. 
The rest of this paper is organized as follows. Section Two presents the existing survey of smart cities design. Section Three elucidates evaluation criteria requirements of smart cities and highlights the potential of network architectures in addressing these requirements. Section Four presents the network architecture capabilities of the designed system. Section Five summarized the reviewed designs of smart cities and compared these designs. Section Six conclude the differences in the architectures according to the requirements of smart cities, and Section Seven provides the conclusion.

\section{Surveys of Smart City Design}

Various opinions on smart cities have been reported in the literature regarding the applications, criteria, and requirements covered by the underlying framework and design. In this aspect, Zanella, Bui [9] proposed a general framework for smart cities that addresses smart city requirements, which were discussed prior to the proposing stage. The discussion revealed the significance in proposing a design that addresses these requirements. In this paper, the following smart city requirements are discussed: services, infrastructure, and access. A case study was conducted in Padova City to validate the proposed framework against the requirements being discussed. Similarly, smart city requirements are discussed prior to proposing the new smart city design proposed by Jin, Gubbi [10]. Different requirements, namely, services, platforms, IoT infrastructure, connectivity model, and connectivity features, are discussed. The services provided by smart cities have been addressed in the majority of existing studies. Schaffers, Komninos [11] explored the concept of smart cities as a framework with various requirements, namely, services, platforms, and devices. Other literature has stated and discussed similar and other requirements with and without case studies supporting the claimed requirements as summarized in Table 1.

Table 1. Survey of Smart Cities Requirements

\begin{tabular}{|c|c|c|c|c|}
\hline Ref. & Type & Proposed Idea & $\begin{array}{c}\text { Smart City } \\
\text { Requirements }\end{array}$ & $\begin{array}{l}\text { Case } \\
\text { Study }\end{array}$ \\
\hline$[4]$ & $\begin{array}{l}\text { IOT \& } \\
\text { Smart } \\
\text { City }\end{array}$ & $\begin{array}{l}\text { Discussed various smart city requirements. } \\
\text { Proposed a general reference framework to design of an } \\
\text { urban Internet of Things. } \\
\text { Presented an experimental study on PADOVA. }\end{array}$ & $\begin{array}{l}\text { Services, IoT- } \\
\text { Infrastructure, Access }\end{array}$ & Yes \\
\hline$[7]$ & $\begin{array}{l}\text { IOT \& } \\
\text { Smart } \\
\text { City }\end{array}$ & $\begin{array}{l}\text { Discussed various smart city requirements. } \\
\text { Presented a framework for centrally controlled smart } \\
\text { city. }\end{array}$ & \begin{tabular}{|l|} 
Services, Platforms, \\
IoT-Infrastructure, \\
Connectivity Model, \\
Connectivity Features
\end{tabular} & Yes \\
\hline [9] & $\begin{array}{l}\text { Smart } \\
\text { City }\end{array}$ & $\begin{array}{l}\text { Explored the concept of smart cities as a framework with } \\
\text { various requirements. }\end{array}$ & $\begin{array}{l}\text { Services, Platforms, } \\
\text { Devices }\end{array}$ & No \\
\hline$[10]$ & $\begin{array}{l}\text { IOT \& } \\
\text { Smart } \\
\text { City }\end{array}$ & $\begin{array}{l}\text { Reviewed variant features and characteristics of the } \\
\text { Internet of Things systems. } \\
\text { Discussed the main components and features of the } \\
\text { smart city. } \\
\text { Presented the main challenges of the smart city. }\end{array}$ & $\begin{array}{l}\text { Devices, Services, } \\
\text { Connectivity Features }\end{array}$ & No \\
\hline$[11]$ & IOT \& & Considered the Internet of Things platforms as a viable & Service, Platforms, & Yes \\
\hline
\end{tabular}




\begin{tabular}{|c|c|c|c|c|}
\hline & $\begin{array}{l}\text { Smart } \\
\text { City }\end{array}$ & $\begin{array}{l}\text { solution to make cities smarter. } \\
\text { Discussed the semantic annotation of the sensors in the } \\
\text { cloud. } \\
\text { Discussed the services that can be implemented and } \\
\text { considered by bridging between the Cloud and the } \\
\text { Internet of Things. }\end{array}$ & Devices & \\
\hline$[12]$ & $\begin{array}{l}\text { Smart } \\
\text { City }\end{array}$ & $\begin{array}{l}\text { Discussed various technologies for smart city. } \\
\text { Overviewed of a novel Wi-Fi technology, currently } \\
\text { under development. } \\
\text { Organized communication between various devices used } \\
\text { in the smart city, such as smart grids, smart meters, } \\
\text { smart houses, Smart healthcare systems, smart industry. }\end{array}$ & $\begin{array}{l}\text { Enabling } \\
\text { Technologies }\end{array}$ & No \\
\hline$[13]$ & $\begin{array}{l}\text { Smart } \\
\text { City }\end{array}$ & Analyzed smart city architectures requirements. & \begin{tabular}{|l|} 
Enabling \\
Technologies, \\
Connectivity Features \\
\end{tabular} & No \\
\hline$[14]$ & $\begin{array}{l}\text { IOT \& } \\
\text { Smart } \\
\text { City }\end{array}$ & $\begin{array}{l}\text { Discussed various definitions and application domains } \\
\text { of smart cities. }\end{array}$ & $\begin{array}{l}\text { Enabling } \\
\text { Technologies }\end{array}$ & No \\
\hline$[15]$ & $\begin{array}{l}\text { IOT \& } \\
\text { Smart } \\
\text { City }\end{array}$ & $\begin{array}{l}\text { Discussed various platforms for smart city. } \\
\text { Reviewed the research efforts made to integrate Internet } \\
\text { of Thing with smart environments. } \\
\text { State of the art Internet of Thing-based smart } \\
\text { environments. }\end{array}$ & Platforms & No \\
\hline$[16]$ & $\begin{array}{l}\text { IOT \& } \\
\text { Smart } \\
\text { City }\end{array}$ & $\begin{array}{l}\text { Provided detailed, categorized and comprehensive } \\
\text { overview of the research on security problem and their } \\
\text { solutions for smart cities. } \\
\text { Discussed various smart city requirements. }\end{array}$ & $\begin{array}{l}\text { Services, Enabling } \\
\text { Technology, Devices }\end{array}$ & No \\
\hline$[17]$ & $\begin{array}{l}\text { Smart } \\
\text { City }\end{array}$ & $\begin{array}{l}\text { Investigated the evolution of smart city and digital city } \\
\text { concepts during the latest twenty years. } \\
\text { Deep analysis and comparison of smart city and digital } \\
\text { city definitions, useful to support both a well-conceived } \\
\text { city development strategy and the design of a } \\
\text { performance evaluation framework. }\end{array}$ & Services & No \\
\hline$[18]$ & $\begin{array}{l}\text { Smart } \\
\text { City }\end{array}$ & $\begin{array}{l}\text { Explored multiple conceptual dimensions of smart city } \\
\text { (technology, people, and institutions). }\end{array}$ & $\begin{array}{l}\text { Service, Enabling } \\
\text { Technology }\end{array}$ & No \\
\hline [19] & $\begin{array}{l}\text { Smart } \\
\text { City }\end{array}$ & $\begin{array}{l}\text { Presented a comprehensive and verified definition of } \\
\text { smart city, based on both a deep literature investigation } \\
\text { about smart city studies and a large survey of smart city } \\
\text { projects in the international panorama. } \\
\text { Discussed various services that can be provided by the } \\
\text { smart city. }\end{array}$ & Services & No \\
\hline$[20]$ & $\begin{array}{l}\text { Smart } \\
\text { City }\end{array}$ & $\begin{array}{l}\text { Overviewed the main smart city applications, and their } \\
\text { implementation status in major cities around the world. } \\
\text { Presented a study of patents on basic smart city } \\
\text { technologies. } \\
\text { Investigated the relation between patented technologies } \\
\text { and current ongoing smart city applications. }\end{array}$ & Services & No \\
\hline$[21]$ & $\begin{array}{l}\text { Smart } \\
\text { City }\end{array}$ & $\begin{array}{l}\text { Reviewed and four strategic choices for smart cities } \\
\text { platforms based on the recent smart city literature and } \\
\text { experience. }\end{array}$ & Services, Platforms & No \\
\hline$[22]$ & $\begin{array}{l}\text { Smart } \\
\text { City }\end{array}$ & Presented an overview of the concept of the smart city. & Services & No \\
\hline$[23]$ & IOT & $\begin{array}{l}\text { Overviewed of the IETF protocol suite proposed to } \\
\text { support the Internet of Things. } \\
\text { Presented the technical challenges and opportunities that } \\
\text { exist in each network layer (Physical layer, MAC layer, }\end{array}$ & $\begin{array}{l}\text { Connectivity Model, } \\
\text { Connectivity Features }\end{array}$ & No \\
\hline
\end{tabular}




\begin{tabular}{|l|l|l|l|l|}
\hline & & 6LowPAN, RPL protocols, CoAP). & & \\
\hline [24] & $\begin{array}{l}\text { Smart } \\
\text { City }\end{array}$ & $\begin{array}{l}\text { Focused on the communications and networking aspect } \\
\text { of the Internet of Thing. } \\
\text { Presented four different Internet of Thing network } \\
\text { architectures spanning various smart city applications. }\end{array}$ & Connectivity Model & Yes \\
\hline [25] & $\begin{array}{l}\text { IOT \& } \\
\text { City }\end{array}$ & $\begin{array}{l}\text { Presented a framework for designing smart cities } \\
\text { through the Internet of Things } \\
\text { Provided the approaches and resolutions that meet } \\
\text { Internet of Thing respective communications, computing } \\
\text { and computation requirements. }\end{array}$ & Services, Platforms & No \\
\hline [8] & $\begin{array}{l}\text { IOT \& } \\
\text { Smart } \\
\text { City }\end{array}$ & $\begin{array}{l}\text { Provided a classification of the Internet of Thing } \\
\text { platforms and proposed a top-level generic Internet of } \\
\text { Thing architecture particularly suited for the creation of } \\
\text { smart cities. }\end{array}$ & $\begin{array}{l}\text { Platforms, IoT- } \\
\text { Infrastructure }\end{array}$ & Yes \\
\hline
\end{tabular}

Four findings are obtained from Table 1. First, a case study is implemented as a validation for the proposed design. Second, the motivation and comparative criteria between the proposed and existing designs are the smart city requirements. Third, each proposed smart city design is developed by analyzing different requirements that are different from one another, although they share many similarities. Each proposed design is qualified according to the stated requirements. Fourth, comprehensive comparison and evaluation of these designs can be conducted on the basis of a comprehensive list of smart city criteria. Thus, this study identifies and discusses the list of requirements before smart city designs are evaluated and compared.

\section{Evaluation Criteria: Smart-City Requirements}

The literature on smart city designs has indicated that smart cities require technologies that support heterogeneity in services, platforms, infrastructures, devices, technologies, and connectivity [1, 5, 27]. Accordingly, the first requirement of a smart city is the capability to provide various services. Services are the beneficial contents provided to receivers, who can be the urban in the smart city. The latter is involved in decision-making, preservation and optimization of natural resources, and future planning of the cities. Common services of smart cities are waste management, air quality monitoring, noise monitoring, traffic congestion control, energy consumption control, smart parking, and monitoring the structural health of historical places and architectures [4]. As discussed before, services are common requirements that have been addressed by the literature on smart city design.

A platform is the foundation that establishes, organizes, and manages the components and services of smart cities. Smart cities should support heterogeneity in platforms, which can be government-, enterprise-, or business-based platforms. Government platforms are concerned about urban control and government services, such as traffic control, citizen security, environmental protection, water conservation, health, and education services that should be controlled, implemented, and monitored by the government. Enterprise platforms focus on services involved in private investments in collaboration with governments in services, such as transportation and 
warehousing. Business-oriented platforms include products that facilitate and advance smart cities [7].

IoT infrastructure is the mechanism of managing hardware components and transmitted data. Given the large number of transmission devices and high volumes of transmitted data in the IoT applications, managing these data and related devices is anything but trivial. Accordingly, various infrastructures have been proposed, each of which has its advantages and disadvantages. As a requirement of smart cities, the utilized infrastructure should optimize the utilization and organization of these data and devices. Three IoT infrastructures, namely, network-, cloud-, and data-centric, are used for smart city implementation [10]. The next section further discusses on IoT infrastructure, considering that the infrastructure is closely related to the network architecture.

Devices and enabled technologies are two related requirements that refer to the type, operating system, and machine language of the devices involved in the smart city infrastructure. Smart cities should enable various technologies and difference devices (e.g., sensors, mobile devices, and data portals) to cover a wide range of services. However, problems arise when connecting various forms of devices and technologies in a single platform. This characteristic is called scalability, which refers to interactions among heterogeneous types of devices, privacy, ubiquitous access, and availability of testbeds. A smart city requirement should enable various devices and technologies while addressing these problems [28].

Connectivity model is the way by which the devices and technologies are connected to each other. Two common models, IP-based (ubiquitous) and autonomic models, are used with wireless sensor networks. These models differ in their connectivity features, namely, coverage, reliability, and responsiveness [29].

Table 2 summarizes the smart city requirements discussed in this section. Overall, these requirements can be classified into core requirements, which are represented by the infrastructure, devices, technologies, and connectivity; and the augmented requirements influenced and controlled by the core requirement, which are the service and platform requirements.

Table 2. Summary of Smart Cities Requirements

\begin{tabular}{|c|c|c|}
\hline Requirements & Definitions & Variabilities / Variability Problems \\
\hline Services & $\begin{array}{l}\text { The beneficial contents that are provided } \\
\text { to the receivers. }\end{array}$ & $\begin{array}{l}\text { Variability: Waste, Air, Noise, Traffic, } \\
\text { Energy, Parking, Historical }\end{array}$ \\
\hline Platforms & $\begin{array}{l}\text { The foundation that is establish, organize } \\
\text { and manage the smart city components } \\
\text { and services }\end{array}$ & $\begin{array}{l}\text { Variability: Government, Enterprises, } \\
\text { Business }\end{array}$ \\
\hline IoT-Infrastructure & $\begin{array}{l}\text { The way by which the hardware } \\
\text { components and the transmitted data is } \\
\text { being managed }\end{array}$ & Variability: Network, Cloud, Data \\
\hline Devices & \multirow{2}{*}{$\begin{array}{l}\text { The type, operating system, machine } \\
\text { language of the involved devices in the } \\
\text { smart city infrastructure. }\end{array}$} & Variability: Sensors, Mobile, Data portals \\
\hline $\begin{array}{l}\text { Enabling } \\
\text { Technologies }\end{array}$ & & $\begin{array}{l}\text { Problems: Scalability, Privacy, Access, } \\
\text { Testbeds }\end{array}$ \\
\hline Connectivity Models & \multirow{2}{*}{$\begin{array}{l}\text { The way by which the devices and } \\
\text { technologies are connected to each other }\end{array}$} & Variability: Ubiquitous, Autonomic \\
\hline $\begin{array}{l}\text { Connectivity } \\
\text { Features }\end{array}$ & & $\begin{array}{l}\text { Variability: Coverage, Reliability, } \\
\text { Responsiveness }\end{array}$ \\
\hline
\end{tabular}




\section{Network Architecture Capabilities}

Network architecture is the condition that wraps the entities, functionalities, scopes, objectives, and communication models of the designed system. All or at least a few of the requirements discussed above for smart cities are controlled by the network architecture used in the underlying design. Network architecture determines the infrastructure, devices, and technologies involved in the network other than the connectivity among the involved devices. The core requirements of smart cities are therefore determined on the basis of the selected architecture, which significantly influences the augmented requirements.

If the network architecture has previously specified the details of the network, the requirements satisfied by the implemented network can be concluded without actual implementing the system. However, different architectures have varied levels of details that specify the network. Certain architectures are concerned about the highlevel details, such as objectives and scopes, whereas others consider the low-level details of data packets and communication protocols. Accordingly, a few of the architectures leave considerable details open for consideration in accordance with the implementation [30]. Even in a general architecture, a few of the requirements discussed in the previous section can be concluded. The common network architectures used with IoT are discussed in this section.

Autonomic networks are developed to overcome the limitations in the Internet architecture by giving flexibility to the networks and the dynamic and fully autonomous node formation. Autonomic devices can communicate with predetermined devices in a specific format. The autonomic network architecture is a good approach for smart cities; however, limitations exist in devices, technologies, and services. Despite such limitations, autonomic networks have a significant feature that "makes network devices intelligent by introducing self-management concepts that simplify network management for the network operator." Figure 2 presents an overview of autonomic networks [31].

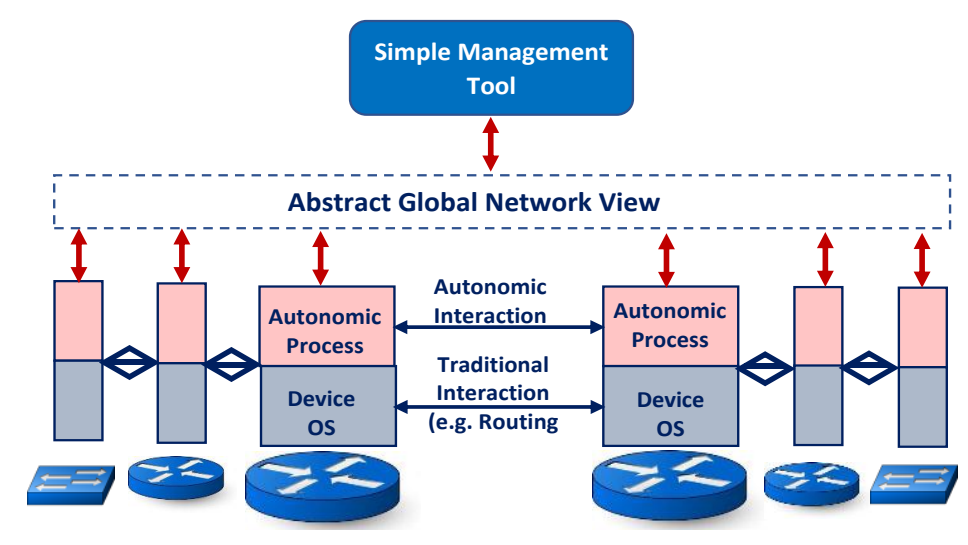

Fig. 2. Autonomic Network 
Ubiquitous network architecture aims at making services and communication available anytime, anywhere, and using any device. Accordingly, the user or the autonomic device can communicate with any other devices in any format. The requirements for this architecture are the Internet, communication protocols, and middleware. The ubiquitous network architecture consists of three layers, namely, the task management layer, which is responsible for monitoring tasks; the environment management layer, which is responsible for resource monitoring and management; and the environment layer, which manages the reliability of the resources. The ubiquitous network architecture is a good approach for smart cities, but scalability, privacy, and testbeds are major problems of this architecture [32].

The application layer architecture determines how an application is organized over various end systems, which is implemented as $\mathrm{P} 2 \mathrm{P}$, client server, and hybrid. Accordingly, the communication is implemented on the basis of a unified application and through any devices in any format. This architecture is not concerned about the low details of packet communication; thus, it leaves a space for extensive implementation, including the utilization of IP-based network architecture [33].

Service-oriented architecture determines how services are being provided to clients and accordingly focuses on communication type to ensure reliable services. Although this architecture is concerned about reliable communication, it ignores the low details of packet transmission and thus leaves a space for extensive implementation, including the utilization of IP-based network architecture [34].

\section{Comparative Study on the Smart Cities Designs}

Various smart city designs have been reported in the literature, with different design requirements that lead to heterogeneous designs. A review of existing designs is presented in this section to highlight the heterogeneity in these designs. The Padova smart city design [9], as illustrated in Figure 3, was developed on the basis of a central-service provider that allows users to gain partial access of data via web services to overcome the interpretability problem with heterogeneous devices. Among various web service standards for the IoT, such as ETSI, SENSEI, IoT-A, and SmartStantender, the Padova design is built in accordance with the IETF standard [35]. A gateway is used for protocol translation (XML-to-EXI, HTTP-to-CoAP and IPv4/v6to-6LoWPAN). Moreover, WAN (Ethernet and WIFI) and Bluetooth IEEE 802.15.4 are utilized when power consumption is restricted. 


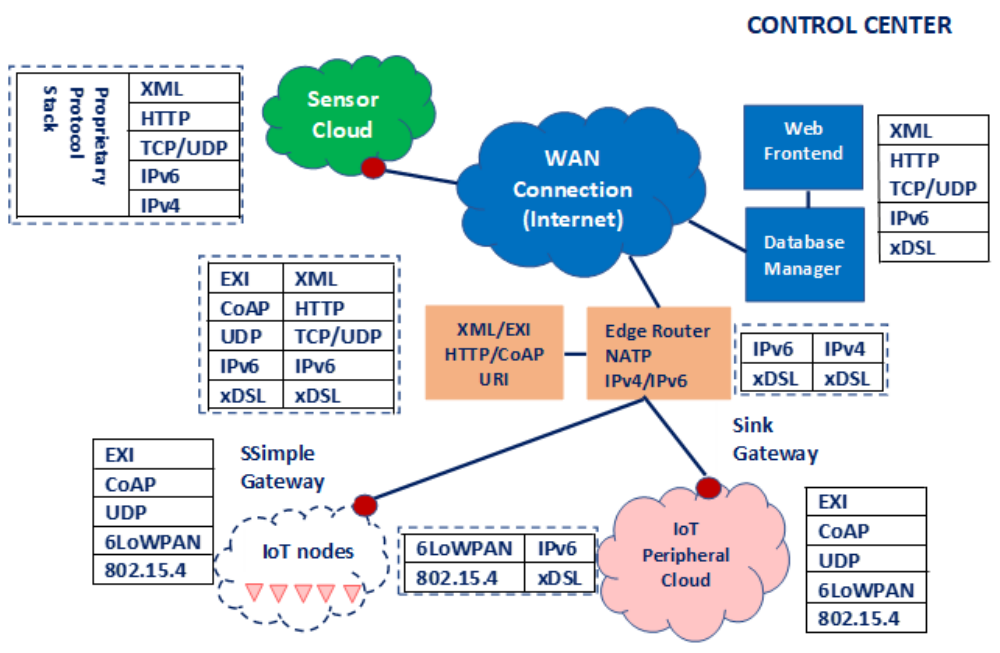

Fig. 3. Padova Smart City Design and Architecture [4]

In Canada, a smart city was implemented in Amazon [7] (see Figure 4). The smart city design is managed by a backend server that is connected to sensors and open-data portals using clouds. The implemented design aims to provide a multiplatform design managed by the government while allowing third parties to provide services through the center hub. A system of systems is established by the backend server, sensor gateway, and cloud service provider. Although being centralized and controlled by a single agent allows the implementation of a multiplatform, the process of handling the scalability issues in the design is unclear.

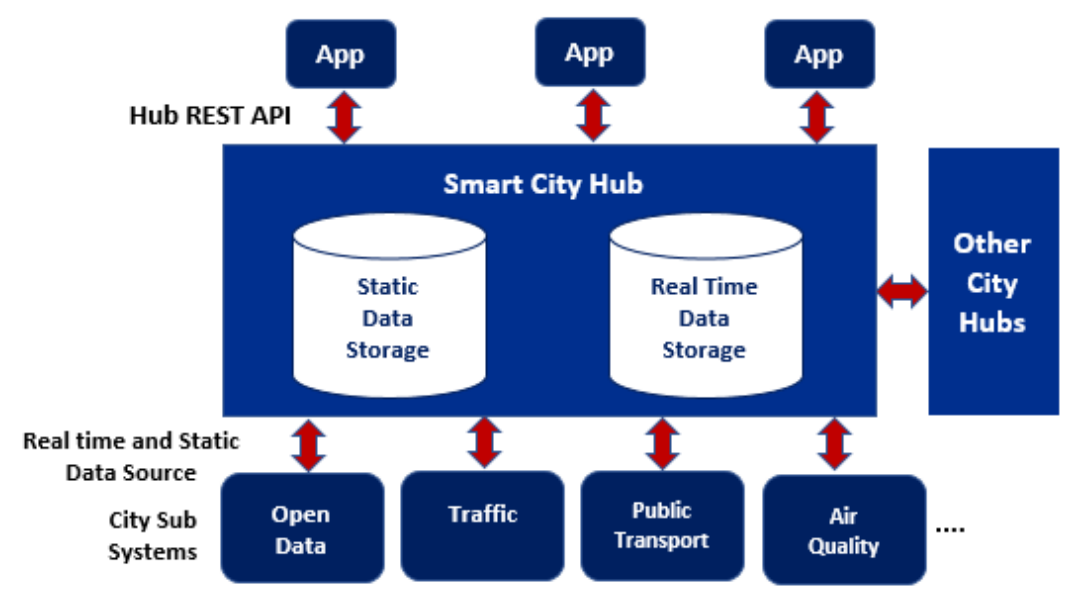

Fig. 4. Amazon Smart City Design and Architecture [6] 
Melbourne smart city design [10] is cloud-based that uses the ICT cloud standard for the IoT. The goal is to develop a smart city that is efficient, interactive, and monitored. The design consists of peripherals for data collection, offline analysis by backend server, and central station to control the system. Compared with other approaches, this system is less autonomous and is run by the central station. This model is more reliable than the previously discussed models, but it cannot support the increment in services provided by various platforms.

A generic smart city design was proposed by Ganchev, Ji [4] using cloud services to facilitate a multiplatform design run by the government and allow third parties to provide services through the center hub. The design is based on backend data center, central management, and application platform. Similar to the system by Lea and Blackstock [7], this system is less autonomous and is run by the central station.

Guadalajara (Mexico) smart city [36-38] is built as an autonomic network of sensors with consideration to provide high interoperability, scaling, and modularity. The data are collected from the sensor network and transferred into the server using HTTP and POST method for information hiding. The collected data are then connected to a web service to be accessed by the user. The problem raised by this approach is the incapability to access data on-demand or to establish real-time data collection because the collection and provision of data are divided into two separate systems.

Trento (Italy) smart city [39] is created simply as a service provider and the concept of a one-stop shop for online services. Trento City aims to offer citizens and enterprises a single access point that is simple, trusted, complete, connected, and open. Accordingly, this system is centralized based that allows enterprises to be linked but indirectly through the government.

Wuxi (China) smart city [40] is made up of a centralized system with multiple applications, which consist of IoT, sensor, radio frequency identification, video detection, and multisource data integration. The challenge of the system is to provide heterogeneous-data-integrated management system and multiply interaction models.

Seoul (South Korea) smart city [41] is built on the basis of a platform owned by the government that is accessible via web browser. This project aims to provide intelligent services to the public. The future plan involves the construction of public data integration with multiple servers to provide various applications for urban services and urban planning.

San Francisco City (USA) smart city [41] is implemented to support the economy, and the private sector is the major contributor of this city plan. The architecture consists of open-data servers that allow private sectors to develop various selfsustaining services for the public. Minimal control is implemented by the government on the data and services provided. Services offered are mostly in restricted and beneficial domains, such as transportation, crime and disaster prevention, tourism, and leisure. Although this approach has gained substantial money-wise benefits, it causes service duplication and ignorance of important urban services.

London (United Kingdom) smart city [42] was built on the same concept as that of San Francisco and started in 2012 for "managing public transport under the demanding circumstances of that year's Olympic Games.” In 2013, the Smart London 
Board was created, and city development plan was initiated with the aim at providing access to open data with the incorporation of private sectors and educational institutions to provide services in various fields.

Stockholm (Sweden) smart city [42] is built with a citizen-centric strategy, "focusing on providing enhanced e-government services to citizens in real time with data that are collected through Global Positioning Systems (GPS) placed on public vehicles, as well as traffic and weather sensors, pollution monitoring equipment, etc."

Although the designs provided are limited, a variation is clearly shown on the basis of the criteria determined earlier. Table 3 summarizes the reviewed designs of smart cities, and Table 4 compares these designs.

Table 3. Existing Smart Cities Architectures

\begin{tabular}{|l|l|l|}
\hline \multicolumn{1}{|c|}{ Design } & \multicolumn{1}{|c|}{ Architecture } & \multicolumn{1}{c|}{ Details } \\
\hline Padova [9] & Service-oriented & $\begin{array}{l}\text { Backend Server (data storage, management and data-access), } \\
\text { Gateways (protocol translation and functional mapping) and } \\
\text { IoT peripheral nodes. }\end{array}$ \\
\hline Amazon [7] & Network-oriented & $\begin{array}{l}\text { Backend Server (service provider), Gateways (sensor data } \\
\text { transmission) and IoT peripheral nodes. }\end{array}$ \\
\hline Melbourne [10] & Service-oriented & $\begin{array}{l}\text { Backend Server (service provider), Gateways (sensor data } \\
\text { transmission) and IoT peripheral nodes. }\end{array}$ \\
\hline Ganchev, Ji [4] & Network-oriented & $\begin{array}{l}\text { Backend Server (service provider), Gateways (sensor data } \\
\text { transmission) and IoT peripheral nodes. }\end{array}$ \\
\hline Mexico [38] & $\begin{array}{l}\text { Autonomic at } \\
\text { collecting side and } \\
\text { service-oriented at } \\
\text { service side. }\end{array}$ & $\begin{array}{l}\text { Backend Server (data storage, management and data-access), } \\
\text { Gateways (data transforming) and IoT peripheral nodes. }\end{array}$ \\
\hline Trento [39] & Service-oriented & Backend Server (data storage, management and data-access). \\
\hline Wuxi [40] & Application-oriented & Backend Server (data storage, management and data-access). \\
\hline Seoul [41] & Network-oriented & $\begin{array}{l}\text { Backend Server (data storage, management and data-access) } \\
\text { and network platform. }\end{array}$ \\
\hline San Francisco [41] & Service-oriented & $\begin{array}{l}\text { Backend Server (data storage, management and data-access) } \\
\text { and network platform }\end{array}$ \\
\hline London [42] & Service-oriented & $\begin{array}{l}\text { Backend Server (data storage, management and data-access) } \\
\text { and network platform }\end{array}$ \\
\hline Stockholm [42] & Service-oriented & $\begin{array}{l}\text { Backend Server (data storage, management and data-access), } \\
\text { Gateways (data transforming) and IoT peripheral nodes. }\end{array}$ \\
\hline
\end{tabular}

Table 4. Existing Smart Cities Comparison

\begin{tabular}{|l|l|l|l|l|l|l|l|l|}
\hline Design & Services & $\begin{array}{l}\text { Interpreta } \\
\text { bility }\end{array}$ & Access & Devices & $\begin{array}{l}\text { Scalab } \\
\text { ility }\end{array}$ & Platforms & Privacy & Reliability \\
\hline Padova [9] & Urban & $\begin{array}{l}\text { Provided } \\
\text { by the } \\
\text { gateways }\end{array}$ & $\begin{array}{l}\text { Partially } \\
\text { controlled } \\
\text { by backend }\end{array}$ & $\begin{array}{l}\text { Sensors for } \\
\text { data-collection } \\
\text { and variety of } \\
\text { access devices }\end{array}$ & $\begin{array}{l}\text { Scalabl } \\
\text { ented }\end{array}$ & Enterprise & Supported & Supported \\
\hline $\begin{array}{l}\text { Amazon } \\
{[7]}\end{array}$ & Urban & $\begin{array}{l}\text { Provided } \\
\text { by the } \\
\text { gateways }\end{array}$ & $\begin{array}{l}\text { Controlled } \\
\text { by backend }\end{array}$ & Sensors & $\begin{array}{l}\text { Limite } \\
\mathrm{d}^{*}\end{array}$ & All** & Supported & Supported \\
\hline $\begin{array}{l}\text { Melbourne } \\
{[10]}\end{array}$ & Urban & $\begin{array}{l}\text { Provided } \\
\text { by the } \\
\text { gateways }\end{array}$ & $\begin{array}{l}\text { Controlled } \\
\text { by backend }\end{array}$ & Sensors & $\begin{array}{l}\text { Limite } \\
\mathrm{d}^{*}\end{array}$ & All** & Supported & $\begin{array}{l}\text { Highly } \\
\text { supported }\end{array}$ \\
\hline
\end{tabular}




\begin{tabular}{|c|c|c|c|c|c|c|c|c|}
\hline $\begin{array}{l}\text { Ganchev, } \\
\text { Ji [4] }\end{array}$ & Urban & $\begin{array}{l}\text { Provided } \\
\text { by the } \\
\text { gateways }\end{array}$ & $\begin{array}{l}\text { Controlled } \\
\text { by backend }\end{array}$ & Sensors & $\begin{array}{l}\text { Limite } \\
\mathrm{d}^{*}\end{array}$ & All** & Supported & Supported \\
\hline $\begin{array}{l}\text { Mexico } \\
{[38]}\end{array}$ & Urban & $\begin{array}{l}\text { Provided } \\
\text { by the } \\
\text { gateways }\end{array}$ & $\begin{array}{l}\text { Fully } \\
\text { controlled } \\
\text { but not } \\
\text { real-time. }\end{array}$ & $\begin{array}{l}\text { Sensors for } \\
\text { data-collection } \\
\text { and variety of } \\
\text { access devices }\end{array}$ & $\begin{array}{l}\text { Scalabl } \\
\text { e }\end{array}$ & Enterprise & Supported & Supported \\
\hline Trento [39] & Urban & $\begin{array}{l}\text { Not } \\
\text { addressed }\end{array}$ & $\begin{array}{l}\text { Fully } \\
\text { controlled } \\
\text { but not } \\
\text { real-time. }\end{array}$ & $\begin{array}{l}\text { Sensors for } \\
\text { data-collection } \\
\text { and variety of } \\
\text { access devices }\end{array}$ & $\begin{array}{l}\text { Not } \\
\text { addres } \\
\text { sed }\end{array}$ & $\begin{array}{l}\text { Governme } \\
\text { nt }\end{array}$ & $\begin{array}{l}\text { Not } \\
\text { addressed }\end{array}$ & $\begin{array}{l}\text { Not } \\
\text { addressed }\end{array}$ \\
\hline Wuxi [40] & Urban & $\begin{array}{l}\text { Not } \\
\text { addressed }\end{array}$ & $\begin{array}{l}\text { Fully } \\
\text { controlled } \\
\text { but not } \\
\text { real-time. }\end{array}$ & Not addressed & $\begin{array}{l}\text { Not } \\
\text { addres } \\
\text { sed }\end{array}$ & $\begin{array}{l}\text { Governme } \\
\text { nt }\end{array}$ & $\begin{array}{l}\text { Not } \\
\text { addressed }\end{array}$ & $\begin{array}{l}\text { Not } \\
\text { addressed }\end{array}$ \\
\hline Seoul [41] & Urban & $\begin{array}{l}\text { Not } \\
\text { addressed }\end{array}$ & $\begin{array}{l}\text { Fully } \\
\text { controlled } \\
\text { but not } \\
\text { real-time. }\end{array}$ & Not addressed & $\begin{array}{l}\text { Not } \\
\text { addres } \\
\text { sed }\end{array}$ & $\begin{array}{l}\text { Governme } \\
\text { nt }\end{array}$ & Supported & Supported \\
\hline \begin{tabular}{|l|} 
San \\
Francisco \\
{$[41]$} \\
\end{tabular} & Urban & $\begin{array}{l}\text { Not } \\
\text { addressed }\end{array}$ & No Control & Not addressed & \begin{tabular}{|l|} 
Not \\
addres \\
sed
\end{tabular} & Companies & Supported & Supported \\
\hline $\begin{array}{l}\text { London } \\
{[42]}\end{array}$ & Urban & $\begin{array}{l}\text { Not } \\
\text { addressed }\end{array}$ & No Control & Not addressed & \begin{tabular}{|l|} 
Not \\
addres \\
sed
\end{tabular} & Companies & Supported & Supported \\
\hline $\begin{array}{l}\text { Stockholm } \\
{[42]}\end{array}$ & Urban & $\begin{array}{l}\text { Not } \\
\text { addressed }\end{array}$ & $\begin{array}{l}\text { Fully } \\
\text { controlled. }\end{array}$ & $\begin{array}{l}\text { Sensors for } \\
\text { data-collection } \\
\text { and variety of } \\
\text { access devices }\end{array}$ & $\begin{array}{l}\text { Not } \\
\text { addres } \\
\text { sed }\end{array}$ & $\begin{array}{l}\text { Governme } \\
\text { nt }\end{array}$ & $\begin{array}{l}\text { Not } \\
\text { addressed }\end{array}$ & $\begin{array}{l}\text { Not } \\
\text { addressed }\end{array}$ \\
\hline
\end{tabular}

*Limited: Supporting a scalability to some-extends. However, full scalability cannot be supported by the underlying design.

**All: Supporting all platform types simultaneously.

Designs vary according to utilized architectures based on the requirements established for each city. In Padova [9], interpretability was the main concern, whereas enabling a multiplatform was the motivation of the design in Amazon [7] and the work by Ganchev, Ji [4]

\section{Concluded Remarks of the Smart-City Requirements}

Services can be provided using any of the network architecture discussed above, except for autonomic networks, which require special equipment that might be unavailable to cover an entire city. Certain limitations are also observed in the ubiquitous architecture owing to the availability of Internet access, which can also propagate to the application- and service-oriented architectures. In terms of platforms, all these architectures can provide various platform supports. Infrastructures are entirely different among these architectures; as the autonomic networks are being automatically connected and configured, only data-centric platforms can be implemented. Ubiquitous network architectures are network centric, which concern transmission and communication and leave the details of data for higher-level applications. Among the main challenges for these architectures are the enabled 
technologies and vulnerability to scalability, privacy, ubiquitous access, and availability of testbeds, which are influenced by the variety of connectivity models provided. Table 5 summarizes the differences in the architectures according to the requirements of smart cities.

The similarities and differences among the architectures discussed and the features of the smart cities imply that different smart city designs based on different architectures can provide different levels of services, interpretability, access, supported devices, scalability, platforms, privacy, and reliability. These variabilities can be used to compare existing smart city designs, alongside the strategy of each city, as will be provided in the next section.

Table 5. Requirements Handling by Network Architectures

\begin{tabular}{|l|l|l|l|l|}
\hline \multicolumn{1}{|c|}{ Requirements } & \multicolumn{1}{|c|}{ Autonomic } & Ubiquitous & \multicolumn{1}{|c|}{ Application-Layer } & Service-Oriented \\
\hline Services & Limited & All & All & All \\
\hline Platforms & All & All & All & All \\
\hline IoT-Infrastructure & Data & Network & All & All \\
\hline Enabling Technologies & $\begin{array}{l}\text { Vulnerable } \\
\text { to access }\end{array}$ & $\begin{array}{l}\text { Vulnerable } \\
\text { to problems }\end{array}$ & $\begin{array}{l}\text { Vulnerable } \\
\text { to access }\end{array}$ & $\begin{array}{l}\text { Vulnerable } \\
\text { to access }\end{array}$ \\
\hline Connectivity Model & Autonomous & Ubiquitous & All & All \\
\hline Connectivity Features & Limited & Good & Limited & Limited \\
\hline Devices & Limited & All & All & All \\
\hline
\end{tabular}

*Limited: Supporting variety of services platforms and etc. to some-extends. However, full support to all possible varieties cannot be supported.

**All: Supporting all the variety of services platforms and etc

\section{Conclusion}

Several smart city designs have been proposed on the basis of various network architectures with different features. Each of the smart city applications is created in accordance with different architectures; hence, interoperability, openness, and convergence problems will be raised. The dynamically changing IoT environment in smart cities also require scalability in adopting new devices, technologies, and environments.

Network architecture affects the efficiency of smart cities and influences other IoT components. Four different network architectures, namely, autonomic, ubiquitous, application-layer overlay, and service-oriented network architectures, generally exist in the smart city domain. Notably, they differ in the connectivity models, QoS, applicability, and suitability for smart city applications.

Different smart city designs based on different architectures can provide different levels of services, interpretability, access, supported devices, scalability, platforms, privacy, and reliability. 


\section{$8 \quad$ References}

[1] Chourabi, H., et al. Understanding smart cities: An integrative framework. in System Science (HICSS), 2012 45th Hawaii International Conference on. 2012. IEEE. https://doi. org/10.1109/hicss.2012.615

[2] Miorandi, D., et al., Internet of things: Vision, applications and research challenges. Ad hoc networks, 2012. 10(7): p. 1497-1516. https://doi.org/10.1016/j.adhoc.2012.02.016

[3] Pan, G., et al., Trace analysis and mining for smart cities: issues, methods, and applications. IEEE Communications Magazine, 2013. 51(6): p. 120-126. https://doi.org/ $10.1109 /$ mcom.2013.6525604

[4] Ganchev, I., Z. Ji, and M. O'Droma, A generic IoT architecture for smart cities. 2014.

[5] Vlacheas, P., et al., Enabling smart cities through a cognitive management framework for the internet of things. IEEE communications magazine, 2013. 51(6): p. 102-111. https:// doi.org/10.1109/mcom.2013.6525602

[6] Sanchez, L., et al., SmartSantander: IoT experimentation over a smart city testbed. Computer Networks, 2014. 61: p. 217-238.

[7] Lea, R. and M. Blackstock. City hub: A cloud-based iot platform for smart cities. in Cloud Computing Technology and Science (CloudCom), 2014 IEEE 6th International Conference on. 2014. IEEE. https://doi.org/10.1109/cloudcom.2014.65

[8] Jin, J., et al. Network architecture and QoS issues in the internet of things for a smart city. in Communications and Information Technologies (ISCIT), 2012 International Symposium on. 2012. IEEE. https://doi.org/10.1109/iscit.2012.6381043

[9] Zanella, A., et al., Internet of things for smart cities. IEEE Internet of Things journal, 2014. 1(1): p. 22-32. https://doi.org/10.1109/jiot.2014.2306328

[10] Jin, J., et al., An information framework for creating a smart city through internet of things. IEEE Internet of Things Journal, 2014. 1(2): p. 112-121. https://doi.org/10.1109/jiot.2013. $\underline{2296516}$

[11] Schaffers, H., et al. Smart cities and the future internet: Towards cooperation frameworks for open innovation. in The future internet assembly. 2011. Springer. https://doi.org/10. 1007/978-3-642-20898-0 31

[12] Arasteh, H., et al. Iot-based smart cities: a survey. in Environment and Electrical Engineering (EEEIC), 2016 IEEE 16th International Conference on. 2016. IEEE. https:// doi.org/10.1109/eeeic.2016.7555867

[13] Petrolo, R., V. Loscri, and N. Mitton, Towards a smart city based on cloud of things, a survey on the smart city vision and paradigms. Transactions on Emerging Telecommunications Technologies, 2017. 28(1). https://doi.org/10.1002/ett.2931

[14] Khorov, E., et al., A survey on IEEE 802.11 ah: An enabling networking technology for smart cities. Computer Communications, 2015. 58: p. 53-69. https://doi.org/10.1016/i.com com.2014.08.008

[15] Da Silva, W.M., et al. Smart cities software architectures: a survey. in Proceedings of the 28th Annual ACM Symposium on Applied Computing. 2013. ACM.

[16] Yin, C., et al., A literature survey on smart cities. Science China Information Sciences, 2015. 58(10): p. 1-18.

[17] Ahmed, E., et al., Internet-of-things-based smart environments: state of the art, taxonomy, and open research challenges. IEEE Wireless Communications, 2016. 23(5): p. 10-16. https://doi.org/10.1109/mwc.2016.7721736

[18] Ijaz, S., et al., Smart cities: A survey on security concerns. Int. J. Adv. Comput. Sci. Appl, 2016. 7(2): p. 612-625. 
[19] Dameri, R. and A. Cocchia. Smart city and digital city: twenty years of terminology evolution. in X Conference of the Italian Chapter of AIS, ITAIS. 2013.

[20] Nam, T. and T.A. Pardo. Conceptualizing smart city with dimensions of technology, people, and institutions. in Proceedings of the 12th annual international digital government research conference: digital government innovation in challenging times. 2011. ACM. https://doi.org/10.1145/2037556.2037602

[21] Dameri, R.P., Searching for smart city definition: a comprehensive proposal. International Journal of Computers \& Technology, 2013. 11(5): p. 2544-2551. https://doi.org/10.24297/ ijct.v11i5.1142

[22] Pellicer, S., et al. A global perspective of smart cities: A survey. in Innovative Mobile and Internet Services in Ubiquitous Computing (IMIS), 2013 Seventh International Conference on. 2013. IEEE. https://doi.org/10.1109/imis.2013.79

[23] Angelidou, M., Smart city policies: A spatial approach. Cities, 2014. 41: p. S3-S11. https:// doi.org/10.1016/j.cities.2014.06.007

[24] Caragliu, A., C. Del Bo, and P. Nijkamp, Smart cities in Europe. Journal of urban technology, 2011. 18(2): p. 65-82. https://doi.org/10.1080/10630732.2011.601117

[25] Sheng, Z., et al., A survey on the ietf protocol suite for the internet of things: Standards, challenges, and opportunities. IEEE Wireless Communications, 2013. 20(6): p. 91-98. https://doi.org/10.1109/mwc.2013.6704479

[26] Jalali, R., K. El-Khatib, and C. McGregor. Smart city architecture for community level services through the internet of things. in Intelligence in Next Generation Networks (ICIN), 2015 18th International Conference on. 2015. IEEE. https://doi.org/10.1109/icin.20 $\underline{15.7073815}$

[27] Balakrishna, C. Enabling technologies for smart city services and applications. in Next Generation Mobile Applications, Services and Technologies (NGMAST), 2012 6th International Conference on. 2012. IEEE. https://doi.org/10.1109/ngmast.2012.51

[28] Ruiz-Romero, S., et al., Integration of distributed generation in the power distribution network: The need for smart grid control systems, communication and equipment for a smart city-Use cases. Renewable and sustainable energy reviews, 2014. 38: p. 223-234. https://doi.org/10.1016/j.rser.2014.05.082

[29] Gardašević, G., et al., The IoT architectural framework, design issues and application domains. Wireless Personal Communications, 2017. 92(1): p. 127-148. https://doi.org/10. 1007/s11277-016-3842-3

[30] Bouabene, G., et al., The autonomic network architecture (ANA). IEEE Journal on Selected Areas in Communications, 2010. 28(1).

[31] IOS, C. Autonomic Networking Configuration Guide, Cisco IOS Release 15E - Autonomic Networking. 2014.

[32] Otto, C., et al., System architecture of a wireless body area sensor network for ubiquitous health monitoring. Journal of mobile multimedia, 2006. 1(4): p. 307-326.

[33] Zegura, E.W., et al., Application-layer anycasting: A server selection architecture and use in a replicated web service. IEEE/ACM Transactions on Networking (TON), 2000. 8(4): p. 455-466. https://doi.org/10.1109/90.865074

[34] Laskey, K.B. and K. Laskey, Service oriented architecture. Wiley Interdisciplinary Reviews: Computational Statistics, 2009. 1(1): p. 101-105. https://doi.org/10.1002/wics.8

[35] Whitehead, E.J. and M. Wiggins, WebDAV: IEFT standard for collaborative authoring on the Web. IEEE Internet Computing, 1998. 2(5): p. 34-40. https://doi.org/10.1109/4236.722 $\underline{228}$

[36] Gonzalez, G. and V. Rosillo, Study and Deployment of Sensor Networks and the Internet of Things in the GDL Smart City. IEEE Guadalajara GDL CCD White Papers, 2015. 
[37] Guerrero-Prez, A., et al., Network architecture based on virtualized networks for smart cities. IEEE-CCD Smart Cities White Paper, Tech. Rep, 2013.

[38] Vázquez-Castañeda, C. and E. Estrada-Guzman, Towards the preparation of the Guadalajara's SmartCity Metrics Structure. IEEE Guadalajara Metrics for Smart Cities Working Group2014, 2014.

[39] Fioroni, G., et al., Smart Government-Toward an Innovative Concept of a "One-Stop Shop" for Interactive Online Services. IEEE-TN Smart Cities White Paper, Trento, Italy, 2014.

[40] Mao, L., W. Fang, and X.-J. Wu, Smart City of Wuxi: Current Situation and Future Plan: IEEE smart city. 2016.

[41] Lee, J.H., M.G. Hancock, and M.-C. Hu, Towards an effective framework for building smart cities: Lessons from Seoul and San Francisco. Technological Forecasting and Social Change, 2014. 89: p. 80-99. https://doi.org/10.1016/j.techfore.2013.08.033

[42] Angelidou, M., Four European smart city strategies. Int'1 J. Soc. Sci. Stud., 2016. 4: p. 18.

[43] Bar-Magen, J. Fog computing: introduction to a new cloud evolution. in Escrituras silenciadas: paisaje como historiografía. 2013. Servicio de Publicaciones.

[44] Yi, S., C. Li, and Q. Li. A survey of fog computing: concepts, applications and issues. in Proceedings of the 2015 Workshop on Mobile Big Data. 2015. ACM. https://doi.org/10.11 $\underline{45 / 2757384.2757397}$

\section{Authors}

Mais Haj Qasem works at King Abdullah II School for Information Technology in The University of Jordan situated at Amman in Jordan.

Wesam AlMobaideen works for The University of Jordan in Amman at Jordan

Article submitted 2018-10-27. Resubmitted 2019-06-03. Final acceptance 2019-10-08. Final version published as submitted by the authors. 